\title{
Implications of focal spinal cord lesions following trauma: evaluation with magnetic resonance imaging
}

\author{
M Silberstein FRACR, O Hennessy FRCR \\ Department of Radiology, Austin Hospital, Heidelberg, Victoria, Australia 3084.
}

\begin{abstract}
In a series of 15 patients who underwent early and follow up magnetic resonance imaging following spinal cord injury, those with focal spinal cord abnormalities such as cord contusion or haematoma had worse neurological outcomes, and most developed spinal cord cysts, showing as well-defined areas of CSF intensity within the cord on T1 weighted images. Patients with cord oedema initially, had better outcomes, with the development of residual areas of myelomalacia. These observations suggest that patients with focal initial spinal cord abnormalities may have an increased risk of developing posttraumatic spinal cord cysts. which may be associated with the development of delayed neurological deterioration.
\end{abstract}

Keywords: magnetic resonance imaging; spinal cord injury; syrinx.

\section{Introduction}

Whilst the development of a cyst or syrinx following spinal cord injury is a not infrequent phenomenon, clinical presentation with symptomatic syringomyelia following spinal trauma is relatively uncommon, with an incidence of between $0.5 \%$ and $3 \%$ amongst different series. ${ }^{1-t}$ Nevertheless, delayed neurological deterioration due to posttraumatic cyst formation is a significant cause of morbidity, and, if left untreated, may result in irretrievable loss of neurological function. ${ }^{3.4}$ The elucidation of the mechanism of spinal cord cavitation resulting in cyst formation had, prior to the development of modern imaging techniques, relied on histopathological studies on necropsy material following demise of spinal cord injured patients ${ }^{2}$ and observations made at the time of surgery. ${ }^{+}$ However, such research cannot identify the initial pathology associated with delayed cyst formation as, in the past, this could not be determined noninvasively.

The relatively recent application of magnetic resonance (MR) imaging to the investigation of spinal trauma has resulted in a noninvasive method of defining the exact nature of the initial injury to the spinal cord, ${ }^{5-7}$ as well as identification of posttraumatic cyst formation in the chronically injured cord. ${ }^{8-10}$ Specific pathological enti- ties such as cord haematoma and cord oedema have been correlated with MR signal abnormalities in the acutely injured cord, ${ }^{5.6}$ whilst cysts and myelomalacia have been documented in the chronically injured cord. ${ }^{8.9}$

The purpose of this study was: (1) to identify whether certain patterns of imaging abnormality on MR are associated with the delayed development of spinal cord cyst; and (2) to attempt to correlate changes in the neurological status following acute spinal trauma with the change in MR appearances of the spinal cord.

\section{Materials and methods}

The patients included in the study were derived from acute admissions to our spinal injuries unit between February 1987 and February 1991. Patients included in the study were examined with MR imaging within 6 weeks of injury, and had follow up examinations at least 6 months from original trauma. Of the 15 patients admitted to the study, 4 had already had MR imaging prior to the commencement of the project for the assessment of new neurological symptoms and a further 11 stable patients were examined prospectively. Of the 4 patients examined for new symptoms, 2 had ascent of neurological level, one had an increase in 
the degree of myelopathty and one had developed increasing muscular spasms. The 15 patients ( 13 males and 2 females) were aged between 12 years and 65 years (mean of 42 years). The mechanism of injury was a motor vehicle accident in 7 patients. a fall in 3 , diving in 2 , an assault in 2 , and recreational sport in one.

All patients included in the study had injuries resulting in neurological impairment at or above T12. Twelve had cervical injuries, and 3 thoracic injuries. The neurological levels of impairment at presentation to hospital were $\mathrm{C} 4-\mathrm{C} 7$ (mode of C5) for cervical injuries, and $\mathrm{T} 2-\mathrm{T} 5$ for thoracic injuries. All patients were initially managed conservatively with temporary spinal immobilisation.

At presentation, the patients underwent clinical and radiological assessments. The pattern of neurological deficit was separated into transverse, central cord syndrome and Brown-Séquard syndrome by the spinal unit physician who examined the patient at presentation, and these categories were included in the study. The examining physicians did not distinguish between anterior cord syndrome and central cord syndrome, so that both of these patterns were described under the latter category.

The pattern of injury was transverse in 7 patients, central cord in 6, and BrownSéquard in 2 patients. Fourteen of the patients had a single level of neurological impairment, and one patient had a complex neurological deficit, which related most closely to the Brown-Séquard pattern.

All patients underwent detailed neurological assessment. This consisted of assessment of the degree of neurological deficit by the method of Frankel et al ${ }^{11}$ at presentation to hospital and at the time of follow up MR: grade A-complete motor and sensory loss; grade $\mathrm{B}$-complete motor loss, but some sensation preserved; grade $\mathrm{C}$-some motor power preserved, but of no functional use; grade D-useful motor function, including walking with aids, but less than normal; grade $\mathrm{E}$-free of neurological symptoms. These assessments were recorded with the pattern type, mode of treatment, and other patient details (a reference number, age, sex and method of injury) independent of the radiological findings. MR imaging was performed on a $0.3 \mathrm{~T}$ resistive MR unit (B3000; Fonar; Melville $\mathrm{NY}$ ) on 13 patients, and on a $1.5 \mathrm{~T}$ superconducting MR unit (Magnetom 63; Siemens; Germany) on 3 patients. The average time from injury to MR examination was 11 days (range 2-41 days), with over $60 \%$ performed within 9 days. Images were obtained with a spin-echo (SE) technique consisting of two sagittal sequences (repetition time msec/echo time msec $=$ $600 / 15$ for T1 weighted images, and 2500/80 for $\mathrm{T} 2$ weighted images), and two axial sequences using similar acquisition times. Flow compensation (gradient moment nulling) was used in the long TR sequences. Slice thickness was $4 \mathrm{~mm}$ with $1 \mathrm{~mm}$ interslice gap.

The spinal cord in each patient was analysed for the presence of four characteristics on MR: transection-defined as partial or complete discontinuity on sagittal images; haematoma - focal high signal on T1 weighted images or low signal on T2 weighted images; contusion-(1) heterogeneous signal from the cord on $\mathrm{T} 1$ or $\mathrm{T} 2$ weighted images, (2) focal area(s) of high signal on T1 images, surrounded by a much larger area of high signal on T2 images, or (3) focal sharply defined area of high signal on T images; and oedema-diffuse, poorly defined high signal on the T2 image with cord expansion, and normal signal on the T1 images.

The follow up MR examinations were performed at a mean of 21 months from injury (range of 6 months to 48 months). MR imaging was performed with a $0.3 \mathrm{~T}$ resistive magnet (B3000; Fonar; Melville NY) on all patients. Images were obtained with a spin-echo (SE) technique consisting of two sagittal sequences (repetition time msec/echo time $\mathrm{msec}=500 / 16$ for $\mathrm{T} 1$ weighted images, and $2500 / 80$ for $\mathrm{T} 2$ weighted images) and two axial sequences $(500 / 16$ and $2500 / 80)$. Slice thickness was $5 \mathrm{~mm}$ with $2 \mathrm{~mm}$ interslice gap. Flow compensation (gradient moment nulling) was used for the long TR sequences.

The MR images were analysed for: cord atrophy, an anteroposterior diameter of less than $6 \mathrm{~mm}$ in the cervical cord, and $5 \mathrm{~mm}$ in 
the thoracic cord on a midline sagittal slice; ${ }^{10}$ myelomalacia, cord hyperintensity on T2 weighted images with either normal or low signal intensity on $\mathrm{T} 1$ weighted images, and ill defined margins of the area of abnormal signal; and cyst, a well defined area of CSF intensity within the cord on T1 weighted images including lesions with surrounding $\mathrm{T} 2$ hyperintensity, if the cystic region was greater than $5 \mathrm{~mm}$ diameter.

The early and follow up images were analysed independently, and the results of the clinical examinations were also recorded independently.

\section{Results}

The results of the clinical and radiological assessments are presented in Table I.

The patients with cord transection had little change over time, although in the second (patient 2), the margins of the cord had retracted slightly by the second examination. This patient also had a second lesion at a lower level, compatible with a contusion. Five of the 6 patients with cord contusion (Fig 1), as well as the patient with a cord haematoma subsequently developed small well defined cystis at the site of the original abnormality, with all 6 presenting as grade $\mathrm{A}$, and none having useful motor function at the outcome.

Of the 5 patients with cord oedema, 3 developed focal areas of myelomalacia located at the centre of the original MR abnormality (Fig 2), and all 3 had useful motor function at follow up. Only one of the patients with cord oedema failed to improve clinically, and on the follow up examination had cord atrophy.

Two patients had normal cords initially, despite the presence of a neurological deficit. One was subsequently examined because of an ascent in the neurological level. at which time he was found to have a small cyst (patient 14). The other patient subsequently presented with increasing myelopathy and was found to have cord atrophy (patient 15).

\section{Discussion}

Descriptions of sequential changes in the MR appearance of the spinal cord and correlation with neurological status have

Table I Initial and follow up MR findings related to change in Frankel grade

\begin{tabular}{|c|c|c|c|c|c|}
\hline \multirow{2}{*}{$\begin{array}{l}\text { No } \\
-\frac{}{1}\end{array}$} & \multicolumn{2}{|c|}{$\begin{array}{l}\text { MR initial } \\
\text { time findings } \\
\text { (days) }\end{array}$} & \multicolumn{2}{|c|}{$\begin{array}{l}\text { MR follow up } \\
\text { time findings } \\
\text { (Mths) }\end{array}$} & \multirow{2}{*}{$\begin{array}{l}\text { Clinical } \\
\text { change }\end{array}$} \\
\hline & 41 & Transection & 16 & Transection & \\
\hline 2 & 15 & $\begin{array}{l}\text { Transection } \\
\text { Contusion }\end{array}$ & 7 & $\begin{array}{l}\text { Transection } \\
\text { Small svrinx }\end{array}$ & $\mathrm{AA}^{\prime}$ \\
\hline 3 & 9 & Contusion & 11 & Small svyrinx & $\mathrm{AC}$ \\
\hline 4 & 4 & Contusion & 13 & Small syrinx & $\mathrm{AB}^{\mathrm{b}}$ \\
\hline 5 & 22 & Contusion & 10 & Small syrinx & $\mathrm{AA}$ \\
\hline 6 & 14 & Contusion & 34 & Small syrinx & $\mathrm{AC}$ \\
\hline 7 & 8 & Haematoma & 26 & Small syrinx & $\mathrm{AA}^{\mathrm{b}}$ \\
\hline 8 & 2 & Contusion & 12 & Normal & $\mathrm{BC}$ \\
\hline 9 & 11 & Oedema & 10 & Cord atrophy & $\mathrm{AA}$ \\
\hline 10 & 2 & Oedema & 23 & Myelomalacia & AD \\
\hline 11 & 3 & Oedema & 28 & Myelomalacia & $\mathrm{AD}$ \\
\hline 12 & 6 & Oedema & 33 & Myelomalacia & $\mathrm{AD}$ \\
\hline 13 & 2 & Oedama & 48 & Normal & $\mathrm{AD}$ \\
\hline 14 & 9 & Norma & 6 & Small syrinx & $\mathrm{CC}^{b}$ \\
\hline 15 & 14 & Normal & 17 & Cord atrophy & $\mathrm{DB}^{b}$ \\
\hline
\end{tabular}

"Patient 2 had two clinical levels.

'Patient 4 had developed increasing spasms: patients 6 and 14 had developed ascent in neurological level; patient 15 had developed increase in degree of myelopathy. 
a

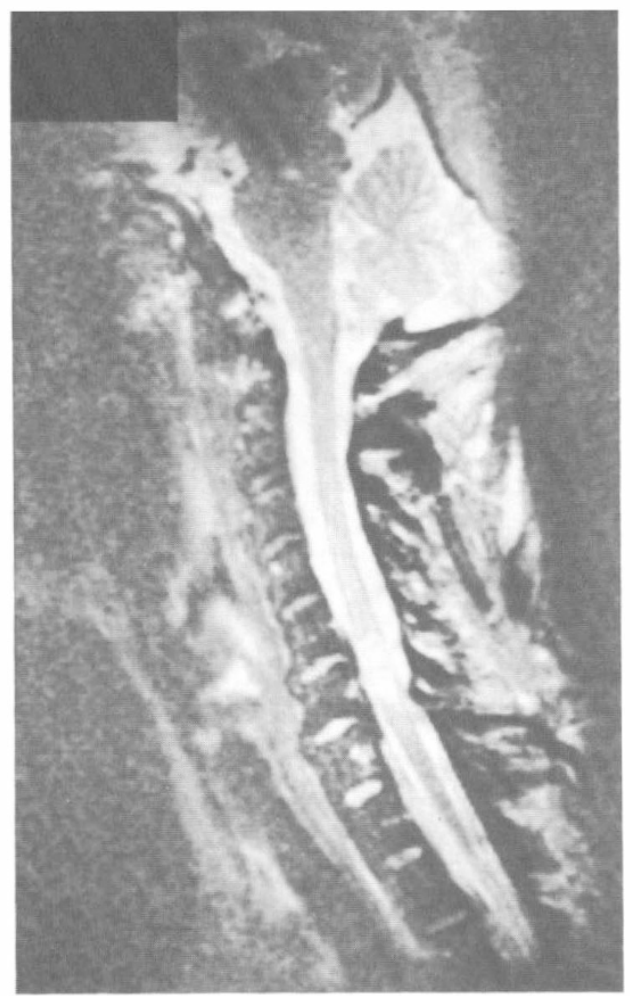

b

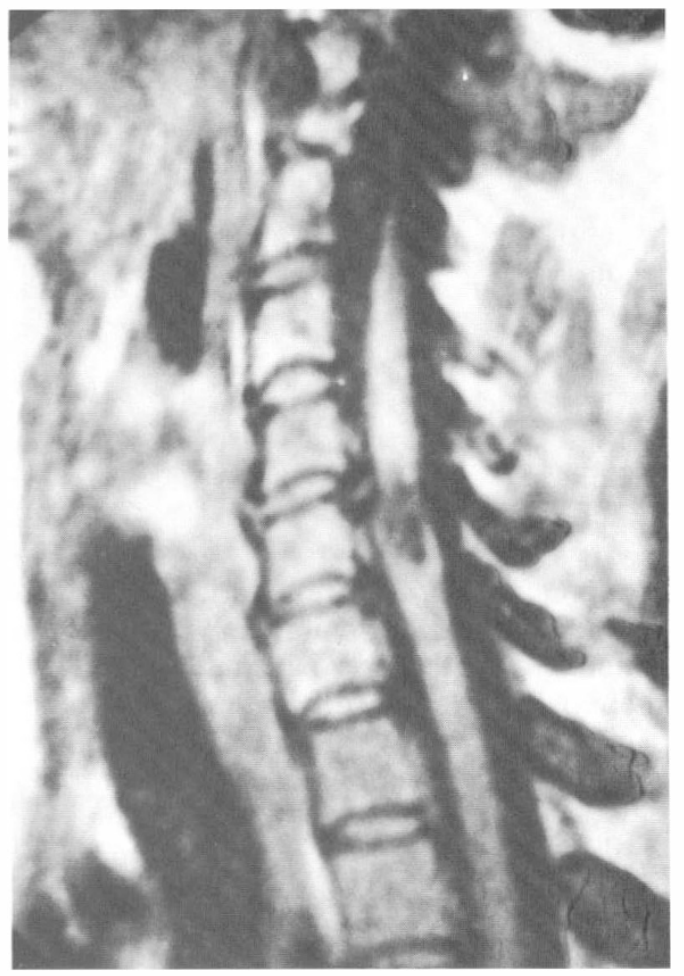

Figure 1 Syrinx arising from a spinal cord contusion in a 50 year old female, initially grade A following a motor car accident resulting in C7 quadriplegia. (a) T2 weighted sagittal image at 22 days from injury demonstrates focal high signal in the cord opposite C6, with surrounding poorly-marginated high signal extending cranially and caudally, consistent with a contusion. (b) T1 weighted sagittal image at 10 months from injury now shows a small syrinx opposite C6. Neurological status was unchanged.

been limited to those provided by Yamashita et $a l^{7,10}$ who, in two papers, described a total of 26 patients who underwent follow up MR imaging following acute trauma. In their series, patients with a hyper- or hypointense signal on the initial $\mathrm{T} 1$ weighted images and a hyperintense signal on T2 weighted images had a low signal on T1 weighted, and a high signal on $\mathrm{T} 2$ weighted images at follow up, with a poor prognosis. ${ }^{10}$ Patients with a normal signal on T1 weighted images, and a high signal on $\mathrm{T} 2$ weighted images at presentation, had a less severe initial neurological deficit, and at follow up those with a persistent signal abnormality had less improvement than those where there was a return of the signal to normal. ${ }^{7}$
By equating the MR imaging appearances found in the patients in our series with pathological entities it is now possible to expand on the results of Yamashita et al. Six of the 7 patients with a cord haematoma or contusion in this series developed well defined lesions of CSF intensity in the cord at the site of original abnormality, satisfying the criteria for small cysts. In all 6, there was no useful motor function at follow up, although in one of these patients the neurological deficit implicated more than one clinical level. In contrast, 3 of the 5 patients with cord oedema developed a focal high signal in the cord on T2 weighted images, with good outcomes. These are likely to represent areas of myelomalacia or gliosis, similar to the $\mathrm{N} / \mathrm{Hi}$ pattern of Yamashita $e t$ 
a

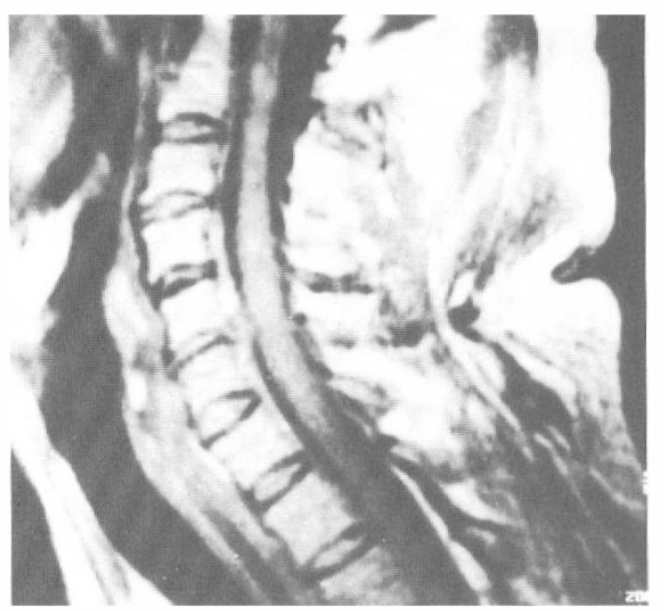

b

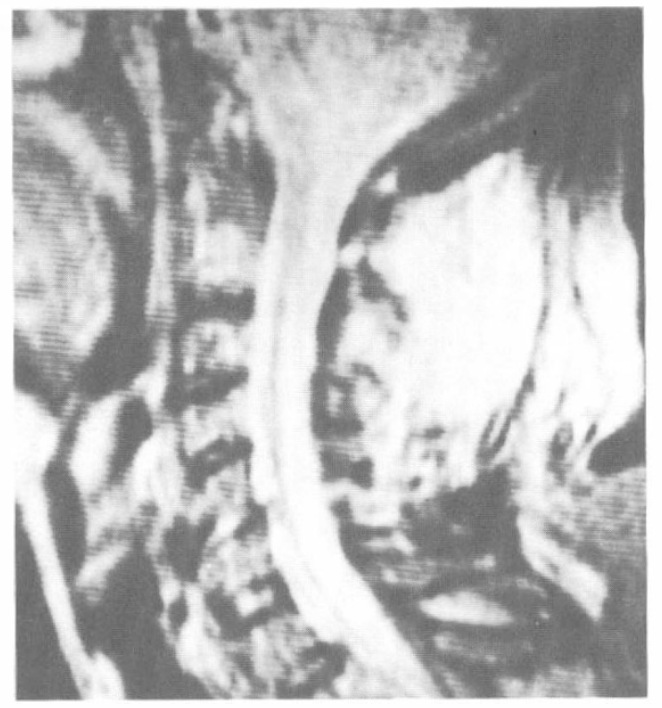

d

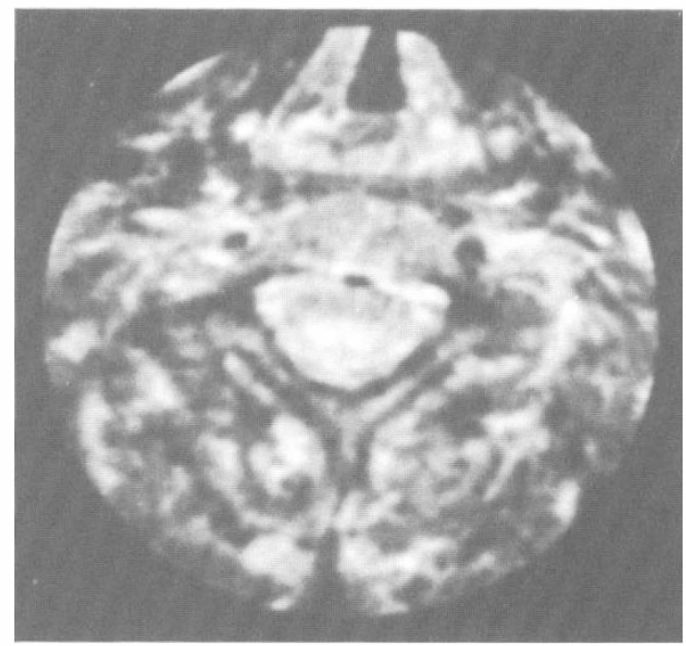

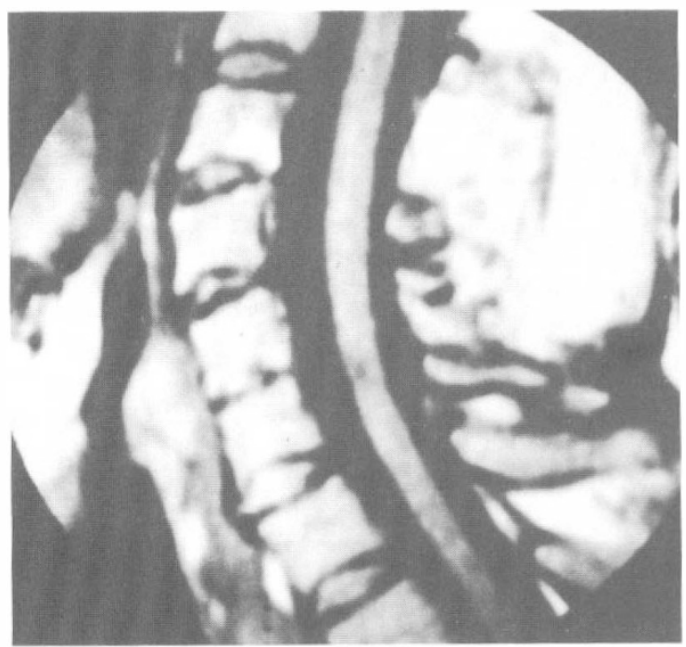

Figure 2 Myelomalacia developing following spinal cord oedema in a 56 year old male, initially grade A following a fall resulting in C6 quadriplegia. (a) T1 weighted sagittal image at 6 days from injury shows a small anterior epidural haematoma with a normal cord. (b) T2 weighted sagittal image. There is extensive cord oedema. (c) T1 weighted sagittal image at 33 months from injury. A small area of low signal consistent with myelomalacia is present opposite C6. (d) T2 weighted axial image through C6. Focal high signal in the cord, consistent with myelomalcia, is confirmed. The patient had improved to grade D at this time.

al, ${ }^{10}$ with a good prognosis. The likely pathological explanations for these changes can be correlated with the MR appearances.

In some patients, pathological examina- tion of the cord at an interval of months or years from trauma shows cystic cavities with fibrous or gliotic walls, whilst in others, especially with lesser degrees of injury, only 
small gliotic foci and small cysts are present. ${ }^{2.8}$ The results of our study suggest that the former group had cord contusions originally, with a poor prognosis and the potential for developing a cyst in the future, whilst the latter group had a less severe injury such as cord oedema, with a better prognosis.

Our results confirm the suggestion made on the basis of pathological studies, that posttraumatic spinal cord cysts initially arise from liquefaction of necrotic cord tissue, rather than from CSF secretion or transudation. 2.12 .13 The patients in this series who developed spinal cord cysts frequently had cord contusions which, on the basis of previous animal experiments, probably represent a combination of central haemorrhage and necrosis. ${ }^{1+}$ Spinal cord haematoma probably represents one end of the spectrum of haemorrhagic contusion, with cyst formation also resulting from liquefaction of contents. This fails to explain the development of a small cyst in one of our patients with an initially normal cord. There are two possible explanation for this phenomenon. Imaging techniques are limited by the ability to resolve very small lesions, so that microscopic foci of haemorrhage may have been present in the cord at the initial examiniation in this patient, but were not identified. Identification of blood products at low field strength MR (which was used in our case) may be difficult in some patients. ${ }^{1+}$ In addition, vascular compression during or after the initial injury is known to be important in the pathogenesis of spinal cord cyst formation, ${ }^{15}$ and may have been a late contributing factor in our case.

The mechanism of formation of foci of myelomalacia in patients with cord oedema is more difficult to explain. Gliotic scars and demyelination have been described in relation to the central grey matter in patients who have less severe spinal injuries (on the basis of no bony injury). ${ }^{2}$ It is likely that these represent the myelomalacia pattern of this study, based on histological and MR studies in patients with chronic cervical cord compression. A number of studies have described focal areas of high signal intensity in the cord on $\mathrm{T} 2$ weighted MR images in patients with chronic cervical cord compression. ${ }^{16,17}$ Histological studies in patients with longstanding cord compression have shown a number of changes, including long tract demyelination, microcystic change and gliosis, with the most severe changes, of necrosis, found in cords with the greatest degree of compression. ${ }^{18}$ The MR findings in this study, whilst similar to those described in patients with chronic cord compression, were, however, associated with a good prognosis, which was not the case in Takahashi et al's large series of patients with nontraumatic cord compression. ${ }^{3}$ Whilst no direct histological correlation is available, it is likely that the changes identified in this study represent changes found in milder degrees of cord compression by Ogino et $a l,{ }^{18}$ such as demyelination and gliosis.

The mechanism by which these changes arise in patients with spinal cord oedema requires elucidation. In patients with chronic cord compression, secondary spinal cord abnormalities are thought to arise, at least in part, from ischaemia secondary to vascular compression, as they are frequently found in terminal supply areas of the anterior spinal artery. ${ }^{19}$ In patients with acute trauma, and subsequent cord oedema, a combination of factors could produce compression of surface and intramedullary vessels. The swollen cord could impinge on the bony spinal canal, compressing the anterior spinl artery, whilst accumulation of fluid in the cord could compress small perforating vessels. In addition, disturbances of the local circulation occur following acute spinal cord injury, due to local release of vasoactive agents, and spinal cord blood flow may decrease dramatically. ${ }^{15,20,21}$

What is the clinical significance of the imaging sequelae identified in this study? Posttraumatic spinal cord cyst formation is an important and treatable cause of delayed neurological deterioration following spinal cord injury. ${ }^{22.23}$ In view of the subsequent development of small cysts in patients with initial cord haematoma or contusion, this group of patients should be monitored closely for the development of this complication. When will patients with posttraumatic spinal cord cysts develop new symptoms, in view of previous descriptions of 
stable patients with spinal cord cysts on MR imaging? ${ }^{10}$ The answer to this question will require prospective serial $\mathrm{MR}$ imaging in large numbers of spinal trauma patients to determine whether, for exmple, the size of the cyst is the most important factor influencing the development of deterioration, as one recent paper has suggested. ${ }^{24}$ This may, in the future, enable the identification of the optimal time for shunting, to reverse the rapid changes accompanying this problem.

\section{Conclusion}

The results of initial and follow up MR imaging in a series of 15 patients with spinal cord injury have been described, and correlated with changes in neurological status.
Patients with focal spinal cord abnormalities such as cord contusion or haematoma, had worse neurological outcomes and most developed small spina cord cysts, whilst patients with cord oedema initially, had better outcomes, with the development of residual areas of myelomalacia. In view of the risk of development of posttraumatic spinal cord cysts in patients with focal spinal cord abnormalities following trauma, they should be closely followed up for the development of neurological deterioration.

\section{Acknowledgement}

The authors express their thanks for the financial assistance of the Edith and Viola Reid Trust of the University of Melbourne.

\section{References}

1 Griffiths ER, McCormick CC (1981) Posttraumatic syringomyelia (cystic myelopathy). Paraplegia 19: 81-88

2 Jellinger K. Pathology of spinal cord trauma (1991). In: Errico TJ, Bauer RD, Waugh T, editors. Spinal Trauma. JB Lippincott, Philadelphia: 455-495.

3 Vernon JD, Silver JR, Ohry A (1982) Post-traumatic syringomyelia. Paraplegia 20: 339-364.

4 Williams B. Post-traumatic syringomyelia, an update (1990) Paraplegia 28: 296-313.

5 Flanders AE, Schaefer MD, Doan HT, Mishkin MM, Gonzalez CF, Northrup BE (1989) Acute cervical spine trauma: Correlation of MR imaging findings with degree of neurologic deficit. Radiology 177: 25-33.

6 Kulkarni MV, Bondurant FJ, Rose SL, Narayana PA (1988) 1.5 Tesla magnetic resonance imaging of acute spinal trauma. Radiographics 8: 1059-1082.

7 Yamashita Y, Takahashi M, Matsuno Y, Sakamoto Y, Oguni T, Sakae T et al (1991) Acute spinal cord injury: magnetic resonance imaging correlated with myelopathy. Br J Radiol 64: 201-209.

8 Gebarski SS, Maynard FW, Gabrielsen TO, Knake JE, Latack JT (1985) Posttraumatic progressive myelopathy. Radiology 157: 379-385.

9 Quencer RM, Sheldon JJ, Donovan Post MJ et al (1986) Magnetic resonance imaging of the chronically injured spinal cord. AJNR 7: 457-464.

10 Yamashita Y, Takahashi M, Matsuno Y, Sakamoto Y, Oguni T, Sakae T et al (1990) Chronic injuries of the spinal cord: assessment with MR imaging. Radiology 175: 849-854.

11 Frankel HL, Hancock DO, Hyslop G, Melzak J, Michaelis LS, Ungar GH et al (1969) The value of postural reduction in the initial management of closed injuries of the spine with paraplegia and tetraplegia. Paraplegia 7: 179-192.

12 Ball MJ, Dayan AD (1972) Pathogenesis of syringomyelia. The Lancet 2: 799-801.

13 Kao CC, Chang LW (1977) The mechanism of spinal cord cavitation following spinal cord transection. Part I. A correlated histochemical study. J Neurosurg 46: 197-209.

14 Schouman-Claeys E, Frija G, Cuenod CA, Begon D, Paraire F, Martin V et al (1990) MR imaging of acute spinal cord injury: Results of an experimental study in dogs. AJNR 11: 959-965.

15 Janssen L, Hansebout RR (1989) Pathogenesis of spinal cord injury and newer treatments: a review. Spine 14: $23-32$.

16 Takahashi M, Sakomoto Y, Miyawaki M, Bussaka H (1987) Increased MR signal intensity secondary to chronic cervical cord compression. Neuroradiology 29: 550-556.

17 Takahashi M, Yamashita Y, Sakamoto Y, Kojima R (1989) Chronic cervical cord compression: clinical significance of increased signal intensity on MR images. Radiology 173: 219-224.

18 Ogino H, Tada K, Okada K, Yonenobuk K, Yamamoto T, Ono K et al (1983) Canal diameter, anteroposterior compression ratio, and spondylotic myelopathy of the cervical spine. Spine 8: 1-15.

19 Hashizume Y, Iijima S, Kishimoto H, Yanagi T (1984) Pathology of spinal cord lesions caused by ossification of the posterior longitudinal ligament. Acta Neuropathol 63: $123-130$.

20 Osterholm JL, Mathews GG (1982) Altered norepinephrine metabolism following experimental spinal cord injury. Part I. Relationșhip to hemorrhagic necrosis and post-wounding neurological deficits. J Neurosurg 36: $386-394$. 
21 Wolman L (1965) The disturbance of circulation in traumatic paraplegia in acute and late stages. Paraplegia 2: $231-236$.

22 Lyons BM, Brown DJ, Calvert JM, Woodward JM, Wriedt CHR (1987) The diagnosis and management of post-traumatic syringomyelia. Paraplegia 25: 340-350.

23 Sett P, Crockard HA (1991) The value of magnetic resonance imaging (MRI) in the follow-up management of spinal cord injury. Paraplegia 26: 396-410.

24 Silberstein M, Hennessy O (1992) Cystic cord lesions and neurological deterioration in spinal cord injury: operative considerations based on magnetic resonance imaging. Paraplegia 30: 661-668. 